OPEN ACCESS

Edited by:

Wei Yang,

Peking University Cancer Hospital,

China

Reviewed by:

Yi Dong,

Fudan University, China

Jie Ren,

The Third Affiliated Hospital of

Sun Yat-Sen University, China

${ }^{*}$ Correspondence:

Li-Ping Sun

sunliping_s@126.com

Kun Zhang

zhang1986kun@126.com

Specialty section:

This article was submitted to

Cancer Imaging and Image-directed

Interventions,

a section of the journal

Frontiers in Oncology

Received: 06 July 2020

Accepted: 21 September 2020

Published: 29 October 2020

Citation:

Bo X-W, LU F, XU H-X, Sun L-P and

Zhang K (2020) Thermal Ablation of Benign Thyroid Nodules and Papillary

Thyroid Microcarcinoma.

Front. Oncol. 10:580431.

doi: 10.3389/fonc.2020.580431

\section{Thermal Ablation of Benign Thyroid Nodules and Papillary Thyroid Microcarcinoma}

\author{
Xiao-Wan Bo ${ }^{1,2,3}$, Feng $\mathrm{Lu}^{1,2,3}$, Hui-Xiong $\mathrm{Xu}^{1,2,3}$, Li-Ping Sun $^{1,2,3^{*}}$ and Kun Zhang ${ }^{1 *}$ \\ ${ }^{1}$ Department of Medical Ultrasound, Shanghai Tenth People's Hospital, Ultrasound Research and Education Institute, Tongji \\ University Cancer Center, Shanghai Engineering Research Center of Ultrasound Diagnosis and Treatment, Tongji University \\ School of Medicine, Shanghai, China, ${ }^{2}$ Thyroid Institute, Tongji University School of Medicine, Shanghai, China, \\ ${ }^{3}$ Department of Medical Ultrasound, Shanghai Center for Thyroid Diseases, Shanghai, China
}

Due to the increasing rates of physical examination and application of advanced ultrasound machines, incidences of benign thyroid nodules (BTNs) and papillary thyroid microcarcinoma (PTMC) were dramatically up-regulated in recent years. Thermal ablation (TA) has been widely used and regarded as a safe and effective method to eliminate or reduce BTNs and recurrent low-risk PTMC. However, conclusions using TA to treat primary PTMC are controversial. Recently, several long-term and prospective studies on TA treatment of BTNs and primary PTMC have been reported. Here, we review current literatures and progress on TA treatment of BTNs and PTMC and underline the way to get the best treatment outcomes, providing a comprehensive insight into the research progresses in this field.

Keywords: thyroid nodules, benign thyroid nodules, primary papillary thyroid microcarcinoma, recurrent papillary thyroid microcarcinoma, thermal ablation

\section{INTRODUCTION}

Thyroid nodules are frequently detected due to the application of ultrasound examination in recent years (1-5). Most of the nodules are benign thyroid nodules (BTNs) or papillary thyroid microcarcinoma (PTMC). Of note, papillary thyroid carcinoma (PTC) is the most common thyroid cancer but features excellent prognosis and low mortality rate $(5,6)$. Though active surveillance was recommended for the low-risk PTMC, patients with low-risk PTMC often received aggressive over-treatments (7). Thyroidectomy is the first-line treatment method for BTNs and PTMC according to the 2015 ATA guidelines and 2016 Chinese expert consensus and guidelines (4, $5,7-9)$. However, limitations remain unavoidable in reality. On one hand, a few patients may feel fear about or not be appropriate for surgery. On the other hand, thyroidectomy will leave permanent scars and require long-time levothyroxine sodium tablets after surgery, which will cause patients, especially young females, to worry about this treatment. Therefore, alternative minimally surgical techniques or non-surgical invasive treatment methods for thyroid nodules are needed.

Percutaneous chemical ablation (ethanol ablation [EA] or polidocanol injection) was usually used to treat cystic or predominantly cystic BTNs (10-15). Thermal ablation (TA), including radiofrequency ablation (RFA), microwave ablation (MWA), laser ablation (LA), and high intensity focused ultrasound (HIFU), were generally applied for solid or mixed BTNs (15-17). TA therapy for 
BTNs has been widely utilized across many countries with good efficacy and safety, as revealed by multi-center studies, longitudinal observational studies, guidelines, as well as metaanalyses (18-23). Nevertheless, not all BTNs were appropriate for TA therapy. Long ablation time or multiple ablation operations are needed for the nodules with large sizes. Moreover, fine-needle aspirations (FNA) or core needle biopsy (CNB) was performed to diagnose the thyroid nodules before ablation. However, false negatives may occur in FNA or $\mathrm{CNB}$ as they were not the gold standard.

TA was also used for the treatment of recurrent PTMC (2427). However, the conclusions related to TA of primary PTMC were controversial. Some prospective or retrospective but longterm follow-up studies reported that TA was an effective and safe method for the selected low-risk PTMC (28-30). Before RFA, patients should have no local invasion, regional lymph node, and distant metastasis. Ultrasound and computed tomography (CT) were often used to detect the regional lymph node and distant metastasis (31). However, some regional lymph node metastasis is difficult to detect.

In this present study, we will review the latest progress in TA treatment of BTNs and PTMC to summarize the efficacy and safety of TA techniques, analyze factors related to the efficacy of ablation, and explore future research directions of this topic.

\section{PATIENTS INCLUDED}

The selection of patients before TA is related to the safety and efficacy of TA treatment.

\section{Patients With BTNs}

Patients included for TA are as follows: patients with symptomatic or cosmetic problems; patients fearing malignancy; refusal of or contraindications to surgery or radioiodine therapy. The nodules included for TA are as follows: cytological confirmation of a benign thyroid nodule on two separate ultrasound-guided biopsies (ultrasound-guided FNA or CNB); no malignant US findings; solid, predominantly solid, or cystic thyroid nodules; thyrotoxicosis in cases of autonomously functioning thyroid nodules $(1,16,17,21-23)$.

The exclusion criteria are as follows: pregnant women; history of radiation to the neck; follicular neoplasm; severe bleeding tendency because of coagulation disorder; severe heart failure/ liver failure/respiratory failure or renal failure; no puncture route judged by US; nodules with heavy calcifications (1, 16, 17, 21-23).

\section{Patients With PTMC}

The inclusion criteria are as follows: refusal of or contraindications to surgery (e.g., age $>80$ years or a co-morbidity such as cardiovascular disease, history of stroke, central nervous system vascular malformation, other malignancy, and immunocompromised state); confirmation of PTMC on ultrasound-guided biopsy; no evidence of gross extrathyroidal extension or metastasis (lymphatic or distant metastasis) on both ultrasound and contrast-enhanced computed tomography (CT); either multiple or solitary PTMCs (1, 25-31).

The exclusion criteria are consistent with those patients with BTNs. Moreover, multiple nodules or those PTMCs without ablation safety margin (less than $2 \mathrm{~mm}$ away from the thyroid capsule) were also excluded for TA treatment (1, 25-31).

\section{The Basic Principle of TA}

The basic principle of TA is to use the heat energy generated by RF electrode needle, MW antenna, LA fiber, or HIFU to generate coagulative necrosis of the nodules. The coagulation necrotic tissue cells are dissolved and liquefied by hydrolytic enzymes, and they are finally absorbed by lymphocyte and blood vessels. Then the ablation zone gradually decreases and finally disappears completely.

\section{TA TREATMENT OF BTNS}

\section{RFA}

RFA was first reported for the treatment of BTNs in 2006 (32). In the past 10 years, the safety and efficacy of RFA therapy has been validated by some prospective randomized controlled trials (RCTs) and multicenter researches $(18-23,33)$. The volume reduction rates (VRR) of BTNs were $66.8 \%-68 \%, 63 \%-74.3 \%$, and $70 \%-82 \%$ at 3,6 , and 12 months after RFA, respectively (22, 34-37). Accordingly, therapeutic success (defined as VRR $>50 \%$ ) can be achieved three months after RFA. Intriguingly, some long-term follow-up studies were reported on the efficacy of RFA for BTNs recently $(22,37)$. For example, a prospective multicenter study indicated that the mean VRR was $80.3 \%$, $84.3 \%, 89.2 \%, 91.9 \%$, and $95.3 \%$ at $12,24,36,48$, and 60 months after RFA treatment (22). Similarly, another retrospective longitudinal observational study reported that the mean VRR was $63 \%, 67.4 \%, 66.7 \%, 66.9 \%$, and $66.9 \%$ at the 1-, 2-, 3-, 4-, and 5-year follow-up, respectively (37). Collectively, these long-term follow-up studies showed that VRR remained stable at least one year after RFA.

The symptom and cosmetic problems are the main reasons that patients with BTNs chose to accept treatment. After RFA, patients' symptom and cosmetic scores were significantly decreased during the follow-up period (22, 34-37). No related deaths were found during and after RFA and the major complication rate was less than $2 \%$ (1). Complications such as voice change, pain, hematoma, vomiting, nodule rupture, and Horner syndrome were mostly received after RFA treatment (1). Nevertheless, RFA therapy had fewer complications and pains, preservation of thyroid function as compared with surgery, alongside reduced hospitalization days and increased patients' satisfaction after RFA (22, 38, 39). Moreover, as patients usually get satisfactory results 3 months after treatment and remain stable at 12 months after RFA, RFA could be considered as the first-line treatment for BTNs for selected patients. 


\section{MWA}

Ultrasound-guided percutaneous MWA that was first introduced in 2012 (40) and 2013 in China (41) ranks as the second approach for BTNs treatment. Similar to RFA, MWA is also effective and safe in decreasing the symptom and cosmetic scores for BTNs, even for large $(\geq 3 \mathrm{~cm})$ benign thyroid nodules $(18,42-45)$. The VRR was $54.3 \%-75.1 \%, 68.7 \%-85.2 \%$, and $88.6 \%-96.4 \%$ at the $3-$, 6-, and 12-month follow-up after ablation $(17,42,44)$. RFA and MWA showed approximately identical results considering VRR at 3 months follow-up (46). However, RFA showed higher VRRs at the 6- and 12-month follow-up (45). MWA exhibits advanced advantages compared to thyroid lobectomy including faster recovery, fewer complications, more complete thyroid function preservation, superior esthetic results, less physiologic disruption, less expense, and lower systemic stress response (17, 47-49). In summary, MWA should be also considered as one of the first-line treatments for BTNs, especially for larger BTNs since MWA is expected to be more effective based on previous studies. However, more long-term follow-up studies are needed.

\section{LA}

In 2006, ultrasound-guided LA was first introduced for treating patients with BTNs-bearing who are inoperable or unwilling to operate (50). The safety and efficacy of LA of BTNs also have been widely demonstrated, accompanied with significant and persistent volume reduction and local symptom improvement $(16,51-53)$. The VRR was $55 \%, 49 \%-53 \%, 59 \%-84 \%$ at $3,6,12$ months follow-up after LA, respectively $(51,54-56)$. A threeyear multicenter prospective randomized trial showed that the VRR was 59\%, 60\%, and $57 \%$ at 1,2 , and 3 years after LA, respectively (56). Compared to RFA and MWA, LA showed similar efficacy and safety considering VRR at 3-months followup (56-58). However, the VRR was lower than RFA, but higher than MWA at 6-months follow-up as well as subsequent followups (58-60). From previous literatures, the VRR was relatively low in LA for BTNs. Long-term follow-up studies are also lacking, and more prospective randomized trials are needed to observe efficacy in the future.

\section{HIFU}

HIFU was first reported for the treatment of BTNs in 2011 (61). Subsequently, Lang et al. demonstrated that the mean VRR was $68.87 \%$ after 12 -month post-HIFU for 22 patients by using nodule volume as the sole determinant of ablation success in a prospective study (62). Lang et al. reported that the mean VRR at $3,6,12,18$, and 24 months was $51.32 \%, 62.99 \%, 68.66 \%, 69.76 \%$, and $70.41 \%$, respectively, after HIFU treatment for 108 patients (63). The pooled VRR was $17.59 \%, 48.93 \%$, and $60.43 \%$ at 1,3 , and 6 months after HIFU for BTNs in a systematic review and meta-analysis (64). However, for larger nodules $(>20 \mathrm{ml})$, additional operations were needed at 3-6 months after initial HIFU treatment $(65,66)$. Compared with open lobectomy, HIFU treatment benefits patients with less treatment time, shortened hospitalization duration, and lower medical cost (67). Noticeably, as a novel and relatively less frequently applied method, HIFU treatment has some drawbacks for the treatment of BTNs, e.g., patients should be stable during HIFU treatment, and longer ablation time and multiple ablation times are needed for patients with large BTNs. Thus, HIFU may be not suitable for patients with large BTNs.

At last, from the long-term retrospective and perspective studies (Table 1), RFA showed more effective consequences in reducing nodule volume compared to LA for the treatment of BTNs. Nevertheless, no studies were found on MWA or HIFU for BTNs with more than 2-years follow-up. In addition, few major complications ( $0 \%-4.2 \%)$ emerged after TA in these longterm follow-up studies (Table 1). The most common complications are voice change, vocal cord paresis, laryngeal nerve palsy, intraoperative hemorrhage, and Horner syndrome according to these long-term follow-up studies (Table 1). Nevertheless, some nodules regrowth $(4.1 \%-20.4 \%)$ after TA still occurred in these studies (Table 1). Thus, more prospective and long-term studies are needed in TA treatment of BTNs to obtain the comprehensive conclusions.

\section{TA TREATMENT OF PTMC}

\section{RFA}

RFA could be considered as an alternative method of reoperation objective to recurrent thyroid cancers, as revealed by multiple studies (24-27). For example, Kim et al. reported comparable recurrencefree survival rates between RFA and reoperation for either 1 year (96.0\% vs. $92.2 \%)$ or 3 year (92.6\% vs. $92.2 \%)$ groups. The posttreatment complication rates (e.g., hoarseness and hypocalcemia) did not differ significantly between the RFA and reoperation groups (24). In another report, Zhang et al. revealed that the mean VRR was $54 \%, 81 \%, 92 \%, 96 \%$, and $100 \%$ at the 1-, 3-, 6-, 12-, and 18 -month after RFA, respectively. No residual or recurrent tumor or complications were found during the follow-up period (26). Chung et al. reported that the VRR of RFA for recurrent PTCs was $99.5 \%$, wherein $91.3 \%$ of the nodules completely disappeared in the mean 80-months follow-up period (27).

Recently, two studies showed that RFA was also an effective and safe method for primary low-risk PTMC with no local tumor progression or distant metastasis during long-term follow-up $(68,69)$. As a paradigm, Cho et al. reported that the complete disappearance rates of primary low-risk PTMC were $98.8 \%$ and $100 \%$ at the 24 - and 60-month follow-up after RFA. During the follow-up period, no local tumor progression and lymphatic or distant metastasis were observed. Concurrently, no patients underwent delayed surgery (68). Zhang et al. found that RFA showed similar oncologic outcomes after over 5 years' follow-up, whereas RFA displayed shorter operation and hospitalization time, lower complications, and less total cost compared with surgery (69). In one study with a large population, 91.4\% (139/ 152) of the ablated low-risk PTMCs completely disappeared with no local or distant recurrence during the mean 39-months follow-up period (31). In terms of health-related life quality, US-guided RFA offers more advantages than surgery, supporting the conclusion that RFA can serve as an alternative strategy for PTMC (70). 


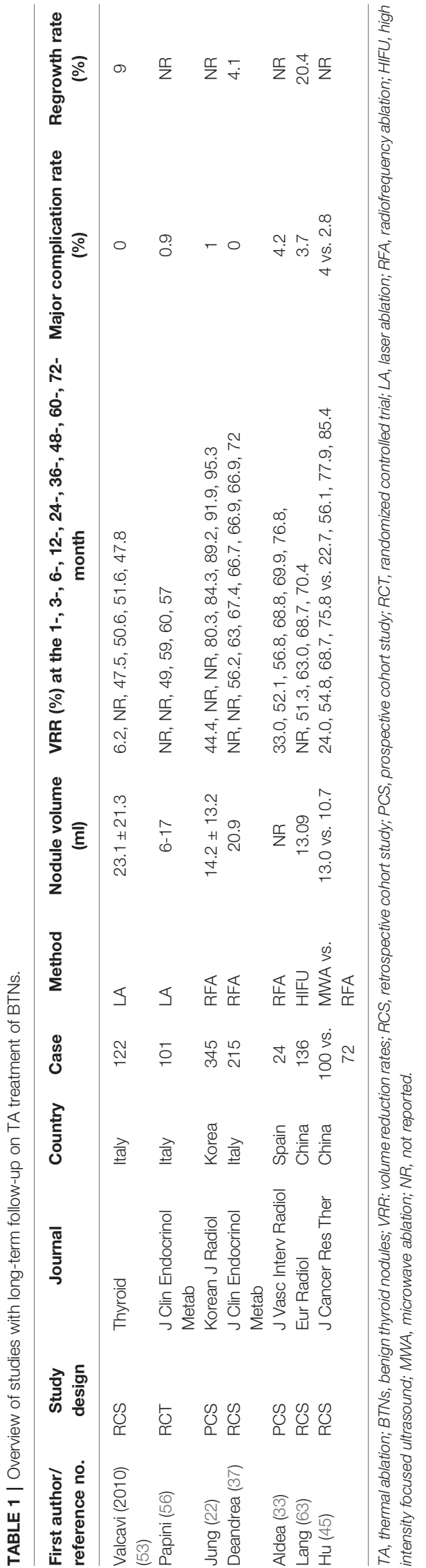

\section{MWA}

In 2014, Yue et al. first used ultrasound-guided percutaneous MWA for treatment with PTMC, and in a mean 11-months' follow-up study, all tumors were completely ablated at a single session and no serious complications occurred (71). Similarly, Teng et al. performed MWA for 21 PTMCs and found that $95.2 \%$ of nodules were completely absorbed with no recurrent nodule after 3 years' follow-up (72). A systematic review and metaanalysis reported that MWA showed significant improvements in nodule volume, clinical symptom scores, and beauty scores between the baseline and final follow-up visits. However, common adverse effects such as hematomas, unbearable pain, and transient or permanent voice change were reported in corresponding $3.8 \%$, $2.2 \%$, and $4.6 \%$ of patients from the 33 original articles, but none of these incidents resulted in patients' hospitalization or death (43). In a 5-year follow-up report, $98.9 \%$ of nodules that were diagnosed to be primary PTMC were completely ablated by MWA, with a VRR of $99.37 \%$ (30). In a prospective study, 119 unifocal PTMC patients were treated with MWA, VRR was $99.4 \%$, and $93.9 \%$ of nodules went into complete remission after mean 37months follow-up. No residual or recurrent nodules after MWA was observed (29). In a large-cohort study consisting of 185 patients with 206 primary PTMCs, the mean VRR at 21-months follow-up was $98.65 \%$ after MWA treatment and $84.5 \%$ of nodules were fully absorbed (73). Collectively, these evidences suggest MWA is safe and effective in primary PTMC treatment and offer a new alternative choice for clinical treatment.

\section{LA}

Papini et al. first used LA for local PTMC treatment in an otherwise inoperable patient with thyroid gland at high surgical risk, indicating LA was a safe and effective ablative method (74). Zhou et al. reported that $96.7 \%(29 / 30)$ of the nodules were successfully ablated after a single session. After 1-year follow-up, $33.3 \%$ of the ablation zones disappeared, and the remaining $66.67 \%$ zones are scar-like nodules. No local recurrence or distant metastases were found in the last follow-up (9). In a retrospective study, the VRR of 81 solitary PTMC treated with LA was $98.4 \%$ after mean 49 -months follow-up. Compared with surgical group, the patients in the LA group showed shorter hospital stay and procedure time and lower complication and recurrence rates (75). In another retrospective study, 37 patients with primary PTMC were treated with LA, and $32.4 \%$ of the treated nodules disappeared and only one patient suffered from cervical lymph node metastasis during 2-years follow-up (76). In summary, LA is also a useful approach for treating primary PTMC.

Interestingly, in the last three years, some long-term followup studies summarized that no local recurrence was found after TA of primary PTMC; the recurrence rates in the remaining thyroid were also very low, and few major complications $(0 \%-$ $2.4 \%$ ) were found during and after the procedure (Table 2). The most common complications are voice change and hoarseness (Table 2). More than $90 \%$ of tumors completely disappeared at the last follow-up period (Table 2). However, there are still some nodules requiring additional ablation owing to the insufficient 


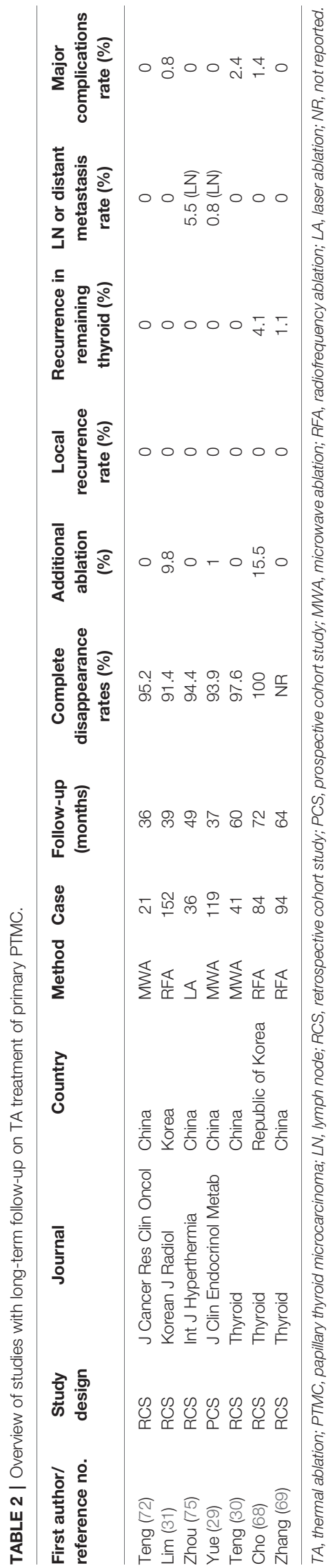

safety margins after the first ablation. In addition, there is no report on the usage of HIFU for the treatment of PTMC yet.

\section{DISCUSSION}

Eliminating the symptoms or cosmetic problems are the main goals of treating those patients with BTNs. Through systematic and comprehensive reviewing of the field's progress, we know that all current TA techniques are effective in reducing VRR and patients' symptoms or cosmetic problems. Fewer complications or adverse events were reported during and after TA for BTNs. Overall, more prospective, multicenter, and long-term follow-up researches were reported in RFA for BTNs than other TA techniques $(18,19,21-23)$. Compared with MWA, LA, or HIFU, RFA showed higher VRRs in studies with long-term follow-up for BTNs. Accordingly, RFA may be the preferred treatment for BTNs, and more studies should be carried out on other TA techniques for BTNs.

The symptoms or cosmetic problems are usually found in patients with large nodules. However, the main factors affecting the incomplete ablation were large size and narrow range adjacent to the danger triangle area or carotid artery or trachea and peripheral blood flow (77). Although the overall successful rate is high, the requirement of second-session TA may occur in those cases that nodules are not completed ablated in the firstsession treatment. Under such conditions, the total expenses will increase as multiple ablations proceed, which may augment the economic burden of these patients. In addition, as the nodules are not completely ablated, the therapeutic success is difficult to achieve, and the regrowth tends to occur more frequently (78). To avoid these inconveniences, the BTNs should be ablated as completely as possible in one-session treatment.

In addition, factors related to VRR should be critically assessed. The initial volume, initially predominant solidity, clear ill-defined margins, applied energy, and initial ablation ratio were the possible predictive factors of VRR (78-82). For example, over $70 \%$ of initial ablation ratio usually predicts VRR of over 50\% after RFA (79). However, Lee et al. reported that the VRR of predominantly cystic vs. predominantly solid nodules was similar at 6-months follow-up in a study consisting of 1,000 patients with 1,619 thyroid nodules (78). Moreover, the hardness of the ablation zone after TA may be another factor affecting the VRR despite no association between them reported currently. Collectively, there are no stable predictors of VRR after TA treatment, and more prospective studies on the factors affecting VRR are needed.

The nodule regrowth in BTNs after TA is a critical concern for patients. It is believed that the factors including larger size, the delivery of lower energy, and incomplete and insufficient ablation of the external border of the nodules correlate with regrowth rates $(82,83)$. Consistent with this, Wang et al. demonstrated that larger initial volume, more irregular blood vessel, and nodules adjacent to the vital structures were found accessible in the recurrence group (84). Recently, Negro et al. suggested that non-spongiform nodules and 12-month VRR < 
$50 \%$ increased the risk of BTNs regrowth after LA in a 5-year follow-up retrospective study (85).

In light of above analysis, the size and location of the nodule are the main factors that affect complete ablation rate, VRR, and nodule regrowth. Regarding this, patients with too large nodules are more suitable for TA. TA can be considered as the first-line treatment for patients with BTNs featuring medium size, even though the symptoms or cosmetic problems are not obvious. However, the specific volume values of larger nodules are uncertain $(20,37,82)$. In addition, the new ablation techniques including artery-first ablation, marginal venous ablation, and hydrodissection technique may be useful to decrease the incomplete ablation rate and repress nodule regrowth (86). Thus, it is speculated that more patients will benefit from TA due to the application of advanced ablation techniques.

Interestingly, the successful ablation rates and VRR of TA for PTMC were higher than TA for BTNs during the follow-up periods. Recent long-term prospective and retrospective studies demonstrated that TA was also effective for primary PTMC due to low complications and recurrences $(29,30,68,87)$. From one recent systematic review and meta-analysis, RFA and MWA for primary PTMC were found to show higher VRR than LA (87). Compared with surgery, TAs need less operation and hospitalization time and have a lower total cost. Patients received better health-related life quality, lower total costs, and stress response $(69,70)$. The major concerns are the lymphatic or distant metastasis in patients with primary PTMC before and after ablation. Actually, low-risk primary PTMCs are rarely found with metastasis, and most metastasis can be found by careful high-resolution ultrasound and CT examination before ablation (7). Moreover, up to now, there have been few researches reporting the local or distant metastasis after TA.

Although patients with low-risk primary PTMC are not recommended for TA treatment, some patients fear metastasis and desire early treatment. Compared with surgery, patients benefit from TA, typically associating with shorter treatment and hospitalization time, lower complications, and no neck scars. Moreover, RFA, MWA, or LA showed similar efficacy and safety on the basis of previous long-term follow-up studies. Taken together, TA is a promising alternative treatment for patients with low-risk primary PTMC.

Although TA is an effective and safe method for the treatment of BTNs and low-risk primary PTMC, some limitations of TA should also receive more attention. First, TA is not suitable for all types of thyroid nodules comparing with surgery, especially for large BTNs, substernal nodules, and deep located nodules. Second, there are still some nodules with incomplete response and local regrowth in the following-up period, which will need repeated ablation or surgery. Third, some nodules shrunk slowly but failed to completely recede according to the current studies. Accordingly, more studies focusing on improving the effectiveness of ablation and reducing local or distant recurrence of nodules are demanded in the future.

\section{Outlook}

In this review, some prospective and prospective clinical studies with long follow-up periods showed that TA was effective and safe for the treatment of BTNs and PTMC. Nevertheless, more prospective randomized controlled trials of large samples comparing TA with surgery with more than five-year follow-up are still absent. Moreover, it is also unsure on whether TA is also effective for the treatment of large PTC or other pathological subtypes of thyroid carcinoma. In addition, the dissolved gas will give birth to bubbles that usually cause strong backscattering ultrasonic signals, which inevitably introduces mistakes into the assessment and monitoring of the ablation process and lesion boundary. To overcome this issue, new imaging technology featuring precise ablation guidance and curative assessment will also be explored. Intriguingly, some fundamental researches on enhancing thermal sensitivity using some enhancement agents were highlighted to improve the utilization efficiency of thermal energy, elevate treatment biosafety, and magnify the ablation outcomes. These impressive cases pave a solid foundation to clinical translation of these enhancement agents via providing theoretical basis and experimental experiences, e.g., RFA enhancement agents, HIFU enhancement agents, etc.

\section{CONCLUSIONS}

Thermal ablation is a promising minimally invasive method and should be considered as the first-line treatment for BTNs and recurrent PTMC. For primary PTMC, TA could be a suitable alternative to surgery for selected patients with low-risk PTMC. However, the suitable included criterion, the ablation equipment selection, and the standard technical operation should be critically evaluated to ensure the best clinical outcomes and complication control after ablation.

\section{AUTHOR CONTRIBUTIONS}

All authors: designed and wrote the manuscript. X-WB, FL: drafted the manuscript and prepared the tables. L-PS, KZ, and $\mathrm{H}-\mathrm{XX}$ : modified the manuscript. All authors contributed to the article and approved the submitted version.

\section{FUNDING}

This work was supported by grants from National Natural Science Foundation of China (Grants 82022033, 81771836, 81501473, 81601501 and 81801802), Shanghai Rising-Star Program (Grant 19QA1406800), Shanghai Talent Development Fund (Grant2019040), Fostering Project of Shanghai Municipal Commission of Health and Family Planning for Excellent Young Medical Scholars (Grant 2018YQ31), the Opening Project of Guangxi Key Laboratory of Bio-targeting Theranostics (GXSWBX201801), the Opening Project of State Key Laboratory of High Performance Ceramics and Superfine Microstructure (SKL201811SIC), Shanghai Municipal Health Commission (Grant201640166), and Shanghai "Rising Stars of Medical Talent” Youth Development Program. 


\section{REFERENCES}

1. Kim JH, Baek JH, Lim HK, Ahn HS, Baek SM, Choi YJ, et al. 2017 Thyroid Radiofrequency Ablation Guideline: Korean Society of Thyroid Radiology. Korean J Radiol (2018) 19:632-55. doi: 10.3348/kjr.2018.19.4.632

2. Davies L, Welch HG. Increasing incidence of thyroid cancer in the United States, 1973-2002. JAMA (2006) 295:2164-7. doi: 10.1001/jama.295.18.2164

3. Burman KD, Wartofsky L. Clinical practice. Thyroid Nodules. N Engl J Med (2015) 373:2347-56. doi: 10.1056/NEJMcp1415786

4. Walsh JP. Managing thyroid disease in general practice. Med J Aust (2016) 205:179-84. doi: 10.5694/mja16.00545

5. Wong R, Farrell SG, Grossmann M. Thyroid nodules: diagnosis and management. Med J Aust (2018) 209:92-8. doi: 10.5694/mja17.01204

6. McLeod DS, Sawka AM, Cooper DS. Controversies in primary treatment of low-risk papillary thyroid cancer. Lancet (2013) 381:1046-57. doi: 10.1016/ S0140-6736(12)62205-3

7. Haugen BR, Alexander EK, Bible KC, Doherty GM, Mandel SJ, Nikiforov YE, et al. 2015 American Thyroid Association Management Guidelines for Adult Patients with Thyroid Nodules and Differentiated Thyroid Cancer: The American Thyroid Association Guidelines Task Force on Thyroid Nodules and Differentiated Thyroid Cancer. Thyroid (2016) 26:1-133. doi: 10.1089/ thy. 2015.0020

8. Brito JP, Hay ID, Morris JC. Low risk papillary thyroid cancer. BMJ (2014) 348:g3045. doi: 10.1136/bmj.g3045

9. Gao M, Ge M, Ji Q, Cheng R, Lu H, Guan H, et al. 2016 Chinese expert consensus and guidelines for the diagnosis and treatment of papillary thyroid microcarcinoma. Cancer Biol Med (2017) 14:203-11. doi: 10.20892/ j.issn.2095-3941.2017.0051

10. Park HS, Yim Y, Baek JH, Choi YJ, Shong YK, Lee JH. Ethanol ablation as a treatment strategy for benign cystic thyroid nodules: a comparison of the ethanol retention and aspiration techniques. Ultrasonography (2019) 38:16671. doi: $10.14366 /$ usg. 18033

11. Iñiguez-Ariza NM, Lee RA, Singh-Ospina NM, Stan MN, Castro MR. Ethanol Ablation for the Treatment of Cystic and Predominantly Cystic Thyroid Nodules. Mayo Clin Proc (2018) 93:1009-17. doi: 10.1016/j.mayocp. 2018.05.020

12. Hahn SY, Shin JH, Na DG, Ha EJ, Ahn HS, Lim HK, et al. Ethanol Ablation of the Thyroid Nodules: 2018 Consensus Statement by the Korean Society of Thyroid Radiology. Korean J Radiol (2019) 20:609-20. doi: 10.3348/kjr.2018.0696

13. Gong X, Zhou Q, Chen S, Wang F, Wu W, Chen X. Efficacy and safety of ultrasound-guided percutaneous polidocanol sclerotherapy in benign predominantly cystic thyroid nodules: a prospective study. Curr Med Res Opin (2017) 33:1505-10. doi: 10.1080/03007995.2017.1325732

14. Sung JY, Baek JH, Kim KS, Lee D, Yoo H, Kim JK, et al. Single-session treatment of benign cystic thyroid nodules with ethanol versus radiofrequency ablation: a prospective randomized study. Radiology (2013) 269:293-300. doi: 10.1148/radiol.13122134

15. Lin Y, Li P, Shi YP, Tang XY, Ding M, He Y, et al. Sequential treatment by polidocanol and radiofrequency ablation of large benign partially cystic thyroid nodules with solid components: Efficacy and safety. Diagn Interv Imaging (2020) 101:365-72. doi: 10.1016/j.diii.2019.11.005

16. Trimboli P, Castellana M, Sconfienza LM, Virili C, Pescatori LC, Cesareo R, et al. Efficacy of thermal ablation in benign non-functioning solid thyroid nodule: A systematic review and meta-analysis. Endocrine (2020) 67:35-43. doi: 10.1007/s12020-019-02019-3

17. Dong P, Wu XL, Sui GQ, Luo Q, Du JR, Wang H, et al. The efficacy and safety of microwave ablation versus lobectomy for the treatment of benign thyroid nodules greater than $4 \mathrm{~cm}$. Endocrine (2020). doi: 10.1007/s12020-020-02338-w

18. Jang SW, Baek JH, Kim JK, Sung JY, Choi H, Lim HK, et al. How to manage the patients with unsatisfactory results after ethanol ablation for thyroid nodules: role of radiofrequency ablation. Eur J Radiol (2012) 81:905-10. doi: 10.1016/j.ejrad.2011.02.039

19. Baek JH, Lee JH, Sung JY, Bae JI, Kim KT, Sim J, et al. Complications encountered in the treatment of benign thyroid nodules with US-guided radiofrequency ablation: a multicenter study. Radiology (2012) 262:335-42. doi: 10.1148/radiol.11110416

20. Huh JY, Baek JH, Choi H, Kim JK, Lee JH. Symptomatic benign thyroid nodules: efficacy of additional radiofrequency ablation treatment session- prospective randomized study. Radiology (2012) 263:909-16. doi: 10.1148/ radiol. 12111300

21. Sung JY, Baek JH, Jung SL, Kim JH, Kim KS, Lee D, et al. Radiofrequency ablation for autonomously functioning thyroid nodules: a multicenter study. Thyroid (2015) 25:112-7. doi: 10.1089/thy.2014.0100

22. Jung SL, Baek JH, Lee JH, Shong YK, Sung JY, Kim KS, et al. Efficacy and Safety of Radiofrequency Ablation for Benign Thyroid Nodules: A Prospective Multicenter Study. Korean J Radiol (2018) 19:167-74. doi: 10.3348/kjr.2018.19.1.167

23. Deandrea M, Sung JY, Limone P, Mormile A, Garino F, Ragazzoni F, et al. Efficacy and Safety of Radiofrequency Ablation Versus Observation for Nonfunctioning Benign Thyroid Nodules: A Randomized Controlled International Collaborative Trial. Thyroid (2015) 25:890-6. doi: 10.1089/ thy.2015.0133

24. Kim JH, Yoo WS, Park YJ, Park DJ, Yun TJ, Choi SH, et al. Efficacy and Safety of Radiofrequency Ablation for Treatment of Locally Recurrent Thyroid Cancers Smaller than $2 \mathrm{~cm}$. Radiology (2015) 276:909-18. doi: 10.1148/ radiol.15140079

25. Suh CH, Baek JH, Choi YJ, Lee JH. Efficacy and Safety of Radiofrequency and Ethanol Ablation for Treating Locally Recurrent Thyroid Cancer: A Systematic Review and Meta-Analysis. Thyroid (2016) 26:420-8. doi: 10.1089/thy.2015.0545

26. Zhang M, Luo Y, Zhang Y, Tang J. Efficacy and Safety of Ultrasound-Guided Radiofrequency Ablation for Treating Low-Risk Papillary Thyroid Microcarcinoma: A Prospective Study. Thyroid (2016) 26:1581-7. doi: 10.1089/thy.2015.0471

27. Chung SR, Baek JH, Choi YJ, Lee JH. Longer-term outcomes of radiofrequency ablation for locally recurrent papillary thyroid cancer. Eur Radiol (2019) 29:4897-903. doi: 10.1007/s00330-019-06063-5

28. Yan L, Lan Y, Xiao J, Lin L, Jiang B, Luo YK. A Long-term outcomes of radiofrequency ablation for unifocal low-risk papillary thyroid microcarcinoma: a large cohort study of 414 patients. Eur Radiol (2020). doi: 10.1007/s00330-020-07128-6

29. Yue WW, Qi L, Wang DD, Yu SJ, Wang XJ, Xu HX, et al. US-guided Microwave Ablation of Low-Risk Papillary Thyroid Microcarcinoma: LongerTerm Results of a Prospective Study. J Clin Endocrinol Metab (2020) 105: dgaa128. doi: 10.1210/clinem/dgaa128

30. Teng D, Li W, Du J, Wang H, Yang D, Wu X. Effects of Microwave Ablation on Papillary Thyroid Microcarcinoma: A Five-Year Follow-Up Report. Thyroid (2020). doi: 10.1089/thy.2020.0049

31. Lim HK, Cho SJ, Baek JH, Lee KD, Son CW, Son JM, et al. US-Guided Radiofrequency Ablation for Low-Risk Papillary Thyroid Microcarcinoma: Efficacy and Safety in a Large Population. Korean J Radiol (2019) 20:1653-61. doi: 10.3348/kjr.2019.0192

32. Kim YS, Rhim H, Tae K, Park DW, Kim ST. Radiofrequency ablation of benign cold thyroid nodules: initial clinical experience. Thyroid (2006) 16:361-7. doi: 10.1089/thy.2006.16.361

33. Aldea Martínez J, Aldea Viana L, López Martínez JL, Ruiz Pérez E. Radiofrequency Ablation of Thyroid Nodules: A Long-Term Prospective Study of 24 Patients. J Vasc Interv Radiol (2019) 30:1567-73. doi: 10.1016/ j.jvir.2019.04.022

34. Deandrea M, Garino F, Alberto M, Garberoglio R, Rossetto R, Bonelli N, et al. Radiofrequency ablation for benign thyroid nodules according to different ultrasound features: an Italian multicentre prospective study. Eur J Endocrinol (2019) 180:79-87. doi: 10.1530/EJE-18-0685

35. Dobnig H, Amrein K. Monopolar Radiofrequency Ablation of Thyroid Nodules: A Prospective Austrian Single-Center Study. Thyroid (2018) 28:472-80. doi: 10.1089/thy.2017.0547

36. Vuong NL, Dinh LQ, Bang HT, Thuy T, Bac NH, Vy TT. Radiofrequency Ablation for Benign Thyroid Nodules: 1-Year Follow-Up in 184 Patients. World J Surg (2019) 43:2447-53. doi: 10.1007/s00268-019-05044-5

37. Deandrea M, Trimboli P, Garino F, Mormile A, Magliona G, Ramunni MJ, et al. Long-Term Efficacy of a Single Session of RFA for Benign Thyroid Nodules: A Longitudinal 5-Year Observational Study. J Clin Endocrinol Metab (2019) 104:3751-6. doi: 10.1210/jc.2018-02808

38. Ha EJ, Baek JH, Lee JH, Sung JY, Lee D, Kim JK, et al. Radiofrequency ablation of benign thyroid nodules does not affect thyroid function in patients with previous lobectomy. Thyroid (2013) 23:289-93. doi: 10.1089/ thy.2012.0171 
39. Choi Y, Jung SL, Bae JS, Lee SH, Jung CK, Jang J, et al. Comparison of efficacy and complications between radiofrequency ablation and repeat surgery in the treatment of locally recurrent thyroid cancers: a single-center propensity score matching study. Int J Hyperthermia (2019) 36:359-67. doi: 10.1080/ 02656736.2019.1571248

40. Feng B, Liang $\mathrm{P}$, Cheng $\mathrm{Z}, \mathrm{Yu} \mathrm{X}, \mathrm{Yu} \mathrm{J}$, Han Z, et al. Ultrasound-guided percutaneous microwave ablation of benign thyroid nodules: experimental and clinical studies. Eur J Endocrinol (2012) 166:1031-7. doi: 10.1530/EJE-110966

41. Yue W, Wang S, Wang B, Xu Q, Yu S, Yonglin Z, et al. Ultrasound guided percutaneous microwave ablation of benign thyroid nodules: safety and imaging follow-up in 222 patients. Eur J Radiol (2013) 82:e11-6. doi: 10.1016/j.ejrad.2012.07.020

42. Khanh HQ, Hung NQ, Vinh VH, Khoi NV, Vuong NL. Efficacy of Microwave Ablation in the Treatment of Large $(\geq 3 \mathrm{~cm})$ Benign Thyroid Nodules. World J Surg (2020) 44:2272-9. doi: 10.1007/s00268-020-05432-2

43. Cui T, Jin C, Jiao D, Teng D, Sui G. Safety and efficacy of microwave ablation for benign thyroid nodules and papillary thyroid microcarcinomas: A systematic review and meta-analysis. Eur J Radiol (2019) 118:58-64. doi: 10.1016/j.ejrad.2019.06.027

44. Zheng BW, Wang JF, Ju JX, Wu T, Tong G, Ren J. Efficacy and safety of cooled and uncooled microwave ablation for the treatment of benign thyroid nodules: a systematic review and meta-analysis. Endocrine (2018) 62:307-17. doi: 10.1007/s12020-018-1693-2

45. Hu K, Wu J, Dong Y, Yan Z, Lu Z, Liu L. Comparison between ultrasoundguided percutaneous radiofrequency and microwave ablation in benign thyroid nodules. J Cancer Res Ther (2019) 15:1535-40. doi: 10.4103/ jcrt.JCRT_322_19

46. Korkusuz Y, Gröner D, Raczynski N, Relin O, Kingeter Y, Grünwald F, et al. Thermal ablation of thyroid nodules: are radiofrequency ablation, microwave ablation and high intensity focused ultrasound equally safe and effective methods. Eur Radiol (2018) 28:929-35. doi: 10.1007/s00330-017-5039-x

47. Yan J, Qiu T, Lu J, Wu Y, Yang Y. Microwave ablation induces a lower systemic stress response in patients than open surgery for treatment of benign thyroid nodules. Int J Hyperthermia (2018) 34:606-10. doi: 10.1080/ 02656736.2018 .1427286

48. Liu SY, Guo WH, Yang B, Li YF, Huang XY, Wang XQ, et al. Comparison of stress response following microwave ablation and surgical resection of benign thyroid nodules. Endocrine (2019) 65:138-43. doi: 10.1007/s12020-01901900-5

49. Zhi X, Zhao N, Liu Y, Liu JB, Teng C, Qian L. Microwave ablation compared to thyroidectomy to treat benign thyroid nodules. Int J Hyperthermia (2018) 34:644-52. doi: 10.1080/02656736.2018.1456677

50. Cakir B, Topaloglu O, Gul K, Agac T, Aydin C, Dirikoc A, et al. Effects of percutaneous laser ablation treatment in benign solitary thyroid nodules on nodule volume, thyroglobulin and anti-thyroglobulin levels, and cytopathology of nodule in $1 \mathrm{yr}$ follow-up. J Endocrinol Invest (2006) 29:876-84. doi: 10.1007/BF03349190

51. Oddo S, Felix E, Mussap M, Giusti M. Quality of Life in Patients Treated with Percutaneous Laser Ablation for Non-Functioning Benign Thyroid Nodules: A Prospective Single-Center Study. Korean J Radiol (2018) 19:175-84. doi: 10.3348/kjr.2018.19.1.175

52. Mauri G, Nicosia L, Della Vigna P, Varano GM, Maiettini D, Bonomo G, et al. Percutaneous laser ablation for benign and malignant thyroid diseases. Ultrasonography (2019) 38:25-36. doi: 10.14366/usg.18034

53. Valcavi R, Riganti F, Bertani A, Formisano D, Pacella CM. Percutaneous laser ablation of cold benign thyroid nodules: a 3-year follow-up study in 122 patients. Thyroid (2010) 20:1253-61. doi: 10.1089/thy.2010.0189

54. Rahal Junior A, Falsarella PM, Mendes GF, Hidal JT, Andreoni DM, Lúcio J, et al. Percutaneous laser ablation of benign thyroid nodules: a one year followup study. Einstein (Sao Paulo) (2018) 16:eAO4279. doi: 10.31744/ einstein_journal/2018AO4279

55. Achille G, Zizzi S, Di Stasio E, Grammatica A, Grammatica L. Ultrasoundguided percutaneous laser ablation in treating symptomatic solid benign thyroid nodules: Our experience in 45 patients. Head Neck (2016) 38:67782. doi: 10.1002/hed.23957

56. Papini E, Rago T, Gambelunghe G, Valcavi R, Bizzarri G, Vitti P, et al. Longterm efficacy of ultrasound-guided laser ablation for benign solid thyroid nodules. Results of a three-year multicenter prospective randomized trial J Clin Endocrinol Metab (2014) 99:3653-9. doi: 10.1210/jc.2014-1826

57. Ben Hamou A, Ghanassia E, Espiard S, Abi Rached H, Jannin A, Correas JM, et al. Safety and efficacy of thermal ablation (radiofrequency and laser): should we treat all types of thyroid nodules? (†). Int J Hyperthermia (2019) 36:66676. doi: 10.1080/02656736.2019.1627432

58. Shi YF, Zhou P, Zhao YF, Liu WG, Tian SM, Liang YP. Microwave Ablation Compared With Laser Ablation for Treating Benign Thyroid Nodules in a Propensity-Score Matching Study. Front Endocrinol (Lausanne) (2019) 10:874. doi: 10.3389/fendo.2019.00874

59. Cesareo R, Pacella CM, Pasqualini V, Campagna G, Iozzino M, Gallo A, et al. Laser Ablation Versus Radiofrequency Ablation for Benign Non-Functioning Thyroid Nodules: Six-Month Results of a Randomized, Parallel, Open-Label, Trial (LARA Trial). Thyroid (2020) 30:847-56. doi: 10.1089/thy.2019.0660

60. Ha EJ, Baek JH, Kim KW, Pyo J, Lee JH, Baek SH, et al. Comparative efficacy of radiofrequency and laser ablation for the treatment of benign thyroid nodules: systematic review including traditional pooling and bayesian network meta-analysis. J Clin Endocrinol Metab (2015) 100:1903-11. doi: $10.1210 /$ jc.2014-4077

61. Esnault O, Franc B, Ménégaux F, Rouxel A, De Kerviler E, Bourrier P, et al. High-intensity focused ultrasound ablation of thyroid nodules: first human feasibility study. Thyroid (2011) 21:965-73. doi: 10.1089/thy.2011.0141

62. Lang BH, Woo YC, Wong C. High-Intensity Focused Ultrasound for Treatment of Symptomatic Benign Thyroid Nodules: A Prospective Study. Radiology (2017) 284:897-906. doi: 10.1148/radiol.2017161640

63. Lang B, Woo YC, Chiu KW. Two-year efficacy of single-session high-intensity focused ultrasound (HIFU) ablation of benign thyroid nodules. Eur Radiol (2019) 29:93-101. doi: 10.1007/s00330-018-5579-8

64. Chung SR, Baek JH, Suh CH, Choi YJ, Lee JH. Efficacy and safety of highintensity focused ultrasound (HIFU) for treating benign thyroid nodules: a systematic review and meta-analysis. Acta Radiol (2020). doi: 10.1177/ 0284185120909339. 284185120909339.

65. Lang BH, Woo YC, Chiu KW. Single-Session High-Intensity Focused Ultrasound Treatment in Large-Sized Benign Thyroid Nodules. Thyroid (2017) 27:714-21. doi: 10.1089/thy.2016.0664

66. Lang B, Woo YC, Chiu KW. Two sequential applications of high-intensity focused ultrasound (HIFU) ablation for large benign thyroid nodules. Eur Radiol (2019) 29:3626-34. doi: 10.1007/s00330-019-06021-1

67. Lang B, Wong C, Ma E, Woo YC. Chiu KW. A propensity-matched analysis of clinical outcomes between open thyroid lobectomy and high-intensity focused ultrasound (HIFU) ablation of benign thyroid nodules. Surgery (2019) 165:85-91. doi: 10.1016/j.surg.2018.05.080

68. Cho SJ, Baek SM, Lim HK, Lee KD, Son JM, Baek JH. Long-Term Follow-Up Results of Ultrasound-Guided Radiofrequency Ablation for Low-Risk Papillary Thyroid Microcarcinoma: More Than 5-Year Follow-Up for 84 Tumors. Thyroid (2020). doi: 10.1089/thy.2020.0106

69. Zhang M, Tufano RP, Russell JO, Zhang Y, Zhang Y, Qiao Z, et al. Ultrasound-Guided Radiofrequency Ablation Versus Surgery for Low-Risk Papillary Thyroid Microcarcinoma: Results of Over 5 Years' Follow-Up. Thyroid (2020) 30:408-17. doi: 10.1089/thy.2019.0147

70. Lan Y, Luo Y, Zhang M, Jin Z, Xiao J, Yan L, et al. Quality of Life in Papillary Thyroid Microcarcinoma Patients Undergoing Radiofrequency Ablation or Surgery: A Comparative Study. Front Endocrinol (Lausanne) (2020) 11:249. doi: $10.3389 /$ fendo.2020.00249

71. Yue W, Wang S, Yu S, Wang B. Ultrasound-guided percutaneous microwave ablation of solitary T1N0M0 papillary thyroid microcarcinoma: initial experience. Int J Hyperthermia (2014) 30:150-7. doi: 10.3109/ 02656736.2014 .885590

72. Teng D, Sui G, Liu C, Wang Y, Xia Y, Wang H. Long-term efficacy of ultrasound-guided low power microwave ablation for the treatment of primary papillary thyroid microcarcinoma: a 3-year follow-up study. J Cancer Res Clin Oncol (2018) 144:771-9. doi: 10.1007/s00432-018-2607-7

73. Teng DK, Li HQ, Sui GQ, Lin YQ, Luo Q, Fu P, et al. Preliminary report of microwave ablation for the primary papillary thyroid microcarcinoma: a large-cohort of 185 patients feasibility study. Endocrine (2019) 64:109-17. doi: 10.1007/s12020-019-01868-2

74. Papini E, Guglielmi R, Gharib H, Misischi I, Graziano F, Chianelli M, et al. Ultrasound-guided laser ablation of incidental papillary thyroid 
microcarcinoma: a potential therapeutic approach in patients at surgical risk. Thyroid (2011) 21:917-20. doi: 10.1089/thy.2010.0447

75. Zhou W, Ni X, Xu S, Zhang L, Chen Y, Zhan W. Ultrasound-guided laser ablation versus surgery for solitary papillary thyroid microcarcinoma: a retrospective study. Int J Hyperthermia (2019) 36:897-904. doi: 10.1080/ 02656736.2019 .1649475

76. Ji L, Wu Q, Gu J, Deng X, Zhou W, Fan X, et al. Ultrasound-guided percutaneous laser ablation for papillary thyroid microcarcinoma: a retrospective analysis of 37 patients. Cancer Imaging (2019) 19:16. doi: 10.1186/s40644-019-0204-x

77. Zhao CK, Xu HX, Lu F, Sun LP, He YP, Guo LH, et al. Factors associated with initial incomplete ablation for benign thyroid nodules after radiofrequency ablation: First results of CEUS evaluation. Clin Hemorheol Microcirc (2017) 65:393-405. doi: 10.3233/CH-16208

78. Lee GM, You JY, Kim HY, Chai YJ, Kim HK, Dionigi G, et al. Successful radiofrequency ablation strategies for benign thyroid nodules. Endocrine (2019) 64:316-21. doi: 10.1007/s12020-018-1829-4

79. Sim JS, Baek JH, Cho W. Initial Ablation Ratio: Quantitative Value Predicting the Therapeutic Success of Thyroid Radiofrequency Ablation. Thyroid (2018) 28:1443-9. doi: 10.1089/thy.2018.0180

80. Lee JH, Kim YS, Lee D, Choi H, Yoo H, Baek JH. Radiofrequency ablation (RFA) of benign thyroid nodules in patients with incompletely resolved clinical problems after ethanol ablation (EA). World J Surg (2010) 34:148893. doi: 10.1007/s00268-010-0565-6

81. Ahn HS, Kim SJ, Park SH, Seo M. Radiofrequency ablation of benign thyroid nodules: evaluation of the treatment efficacy using ultrasonography. Ultrasonography (2016) 35:244-52. doi: 10.14366/usg.15083

82. Cesareo R, Naciu AM, Iozzino M, Pasqualini V, Simeoni C, Casini A, et al. Nodule size as predictive factor of efficacy of radiofrequency ablation in treating autonomously functioning thyroid nodules. Int $J$ Hyperthermia (2018) 34:617-23. doi: 10.1080/02656736.2018.1430868
83. Sim JS, Baek JH. Long-Term Outcomes Following Thermal Ablation of Benign Thyroid Nodules as an Alternative to Surgery: The Importance of Controlling Regrowth. Endocrinol Metab (Seoul) (2019) 34:117-23. doi: 10.3803/EnM.2019.34.2.117

84. Wang B, Han ZY, Yu J, Cheng Z, Liu F, Yu XL, et al. Factors related to recurrence of the benign non-functioning thyroid nodules after percutaneous microwave ablation. Int J Hyperthermia (2017) 33:459-64. doi: 10.1080/ 02656736.2016 .1274058

85. Negro R, Greco G, Deandrea M, Rucco M, Trimboli P. Twelve-Month Volume Reduction Ratio Predicts Regrowth and Time to Regrowth in Thyroid Nodules Submitted to Laser Ablation: A 5-Year Follow-Up Retrospective Study. Korean J Radiol (2020) 21:764-72. doi: 10.3348/ kjr.2019.0798

86. Park HS, Baek JH, Park AW, Chung SR, Choi YJ, Lee JH. Thyroid Radiofrequency Ablation: Updates on Innovative Devices and Techniques. Korean J Radiol (2017) 18:615-23. doi: 10.3348/kjr.2017.18.4.615

87. Choi Y, Jung SL. Efficacy and Safety of Thermal Ablation Techniques for the Treatment of Primary Papillary Thyroid Microcarcinoma: A Systematic Review and Meta-Analysis. Thyroid (2020) 30:720-31. doi: 10.1089/ thy.2019.0707

Conflict of Interest: The authors declare that the research was conducted in the absence of any commercial or financial relationships that could be construed as a potential conflict of interest.

Copyright (c) $2020 \mathrm{Bo}, \mathrm{Lu}, \mathrm{Xu}$, Sun and Zhang. This is an open-access article distributed under the terms of the Creative Commons Attribution License (CC BY). The use, distribution or reproduction in other forums is permitted, provided the original author(s) and the copyright owner(s) are credited and that the original publication in this journal is cited, in accordance with accepted academic practice. No use, distribution or reproduction is permitted which does not comply with these terms. 